\title{
Spontaneous rupture of a splenotic nodule
}

\author{
Dermot J. Lanigan
}

Department of Surgery, Harold Wood Hospital, Romford, Essex RM3 OBE, UK.

Summary: A case is presented of spontaneous rupture of splenic tissue occurring 14 years after a splenectomy was carried out for trauma. Spontaneous rupture of a splenotic nodule has not previously been described and it may be added to the list of causes of spontaneous haemoperitoneum. The incidence and function of residual splenic tissue are briefly discussed and other causes of splenic rupture are outlined.

\section{Introduction}

Autotransplantation following splenic rupture was described and named splenosis by Buchbinder and Liphoff in $1939^{1}$ and had been found in dogs as early as $1883 .{ }^{2}$ There is some dispute about the incidence $^{3-5}$ of such tissue but several authors have noted that patients who have had a splenectomy for trauma have a lower rate of subsequent serious infection than those for whom this operation has been done for other reasons. ${ }^{6,7}$ Spontaneous rupture of the spleen is a rare, although well-described, event, which may have many causes and which may give rise to diagnostic problems. Although there is one case report of traumatic rupture of a splenotic nodule ${ }^{8}$ our case appears to be the only one on record of its spontaneous rupture.

\section{Case report}

A 27 year old woman was admitted with a short history of left iliac fossa pain which radiated to her back. She had been taking the oral contraceptive pill and denied the possibility of pregnancy. There was no obvious precipitating cause for the pain and she had been completely well until its onset. Fourteen years prior to this admission she had had a splenectomy for trauma. There was nil else of note in her history. On examination she was pale with a pulse rate of 120 per minute and a blood pressure of $90 / 60 \mathrm{mmHg}$. Abdominal examination showed left sided tenderness and guarding. Rectal and vaginal examinations were normal. Her haemoglobin was $10.2 \mathrm{~g} / \mathrm{dl}$ and her white cell count was $8.1 \times 10^{9} / 1$. The clinical impression was of a ruptured ectopic pregnancy. The patient was resuscitated and taken to theatre. A Pfannenstiel

Correspondence: D.J. Lanigan, F.R.C.S.I., Department of Histopathology, Beaumont Hospital, Box 1297, Beaumont Road, Dublin 9, Eire.

Accepted: 25 April 1990 incision was made, $1400 \mathrm{ml}$ of blood were evacuated from the peritoneal cavity and it was determined that the reproductive organs were normal. A left upper paramedian incision was then made. A retroperitoneal haematoma was found in the left upper quadrant and the left colon was mobilized. A splenotic nodule measuring $5 \mathrm{~cm}$ in diameter was found in the centre of the haematoma. Its capsule had ruptured and it was excised. A drain was inserted and the wound closed. The patient made an excellent postoperative recovery complicated only by a mild allergic reaction to amoxycillin. This consisted of a skin rash which resolved on withdrawal of the drug. The patient's white cell count was not elevated at any stage and no specific investigations were carried out. Histology confirmed that the abdominal mass consisted of splenic tissue.

One year later the patient required repair of a small incisional hernia. She has been well since.

\section{Discussion}

Livingstone $e t$ al. ${ }^{3}$ found an incidence of splenosis of $26 \%$ in a study of 23 patients who had had a splenectomy for trauma, but higher figures have been quoted by other authors; a scintigraphic study by Solheim and Nerdrum found evidence of it in $11 / 12$ patients splenectomized for trauma. ${ }^{9}$ Certainly the incidence and function of splenosis are not sufficient to guarantee protection from overwhelming post-splenectomy sepsis and vaccination or antibiotic treatment is still warranted. Accessory spleens have been found in $20 \%$ of patients undergoing splenectomy for staging of Hodgkin's disease 4 and may give rise to recurrence of those haematological diseases for which the procedure is still carried out.

Spontaneous rupture of the normal spleen is an exceedingly rare event ${ }^{10,11}$ and, as in our patient, has caused diagnostic difficulties in women of 
childbearing years. Spontaneous rupture of the diseased spleen has been described in a variety of conditions and is termed 'pathological rupture'. This often fatal complication has been seen in such generally benign conditions as infectious mononucleosis, ${ }^{12,13}$ chicken pox ${ }^{14}$ and salmonella infection $^{15}$ as well as such disorders as rheumatoid arthritis ${ }^{16}$ congenital afibrinogenaemia,${ }^{17}$ acquired immune deficiency syndrome,$^{18}$ amyloidosis ${ }^{19}$ and infective endocarditis. ${ }^{20}$ Other diseases which have been reported to number this event among their rare complications include: chronic pancreatitis, ${ }^{21,22}$ hepatitis $\mathrm{A}^{23}$ and portal hypertension. ${ }^{24} \mathrm{We}$ are uncertain as to the cause of the rupture in our patient. The clinical course (rapid onset of and recovery from her acute abdomen with an absence of other symptoms) does not suggest any particular aetiological factor. Her white cell count was not elevated during her admission and the differential count was normal. Her reaction to amoxycillin is suggestive of infectious mononucleosis although, as no specific serological investigations were carried out, this putative diagnosis cannot be confirmed.

The findings in our patient raise a number of points. Firstly, as splenic tissue may regrow, the need for complete removal of the intact spleen (with a thorough check being made for accessory spleens) in cases of those blood disorders for which it is indicated is emphasized. Secondly, although residual splenic tissue may have some degree of function and the placing of slivers of spleen in the abdomen after splenectomy is worthwhile, it does not offer complete protection and administration of polyvalent pneumococcal vaccine is still recommended. In addition to the mimicking of ruptured ectopic pregnancy by splenic tissue, splenosis can cause further problems for surgeons and gynaecologists by being difficult to distinguish from metastatic carcinoma or endometriosis at laparotomy. ${ }^{25-27}$

No other case of spontaneous rupture of recrudescent or residual splenic tissue has been found on record and, of course, ruptured ectopic pregnancy is still the most likely cause of spontaneous haemoperitoneum in women of childbearing age.

\section{Acknowledgement}

I am grateful to Mr T.P. Brock F.R.C.S. for permission to report this case.

\section{References}

1. Buchbinder, J.H. \& Liphoff, C.J. Multiple peritoneal splenic implants following splenic injury. Surgery 1939, 6: 927-934.

2. Griffini, L. \& Tizzani, G. Etude experimentale sur la reproduction de la rate. Arch Ital Biol 1883, 4: 303-359.

3. Livingstone, C.D., Levine, B.A., Lecklitner, M.L. \& Sirinck, K.R. Incidence and function of residual splenic tissue following splenectomy for trauma in adults. Arch Surg 1983, 118: 617-620.

4. Traetow, W.D., Fabri, P.J. \& Carey, L.C. Changing indications for splenectomy: 30 years experience. Arch Surg 1980, 115: $346-407$.

5. Lanng-Nielsen, J. Splenosis on the right kidney and the diaphragmatic surface following traumatic rupture of the spleen. Acta Chir Scand 1981, 147: 721-724.

6. Walker, H. Splenectomy in childhood: a review in England and Wales 1960-64. Br J Surg 1976, 63: 36-43.

7. Pearson, H.A., Johnston, D., Smith, K.A. et al. The born again spleen. $N$ Engl J Med 1978, 298: 1389-1392.

8. Leker, J.G., Yonehiro, L.R. \& Davis, W.C. Traumatic rupture of splenosis. $J$ Trauma 1985, 25: 560-562.

9. Solheim, K. \& Nerdrum, H.J. Scintigraphic follow-up of splenic rupture. Clin $\mathrm{Nucl}$ Med 1985, 10: 851-854.

10. Holt, S. Spontaneous rupture of a normal spleen diagnosed as ruptured ectopic pregnancy. Two case reports. Br J Obstet Gynaecol 1982, 89: 1062-1063.

11. Lamerton, A.J. Spontaneous rupture of the spleen in early pregnancy. Postgrad Med J 1983, 59: 596-597.

12. Ormann, W. \& Hopf, G. Spontaneous splenic rupture in infectious mononucleosis - organ-sparing operation using fibrin glue. Langenbecks Arch Chir 1988, 373: 240-242.

13. Vitello, J. Spontaneous rupture of the spleen in infectious mononucleosis: a failed attempt at non-operative therapy. $J$ Pediatr Surg 1988, 23: 1043-1044.

14. Lal, P. \& Popple, A.W. Spontaneous rupture of chicken-pox spleen. Br J Surg 1984, 71: 351.
15. Rest, J.G., Seid, A.S., Rogers, D. \& Goldstein, E.J. Pathologic rupture of the spleen due to Salmonella dublin infection. $J$ Trauma 1985, 25: 366-368.

16. Haskard, D.O., Higgens, C.S., Temple, L.N. \& Currey, H.L. Spontaneous rupture of the spleen in rheumatoid arthritis. Ann Rheum Dis 1983, 42: 411-414.

17. Gallet, S., Tran-Minh, V., Louis, D., Cotton, J.B., Berthier, J.C. \& Hartemann, E. Massive haemoperitoneum caused by rupture of the spleen, a complication of congenital afibrinogenaemia. Conservative treatment. [Engl Abstract] Pediatrie 1985, 40: 385-391.

18. Mirchandani, H.G., Mirchandani, I.H. \& Pak, M.S. Spontaneous rupture of the spleen due to acquired immune deficiency syndrome in an intravenous drug abuser. Arch Pathol Lab Med 1985, 109: 1114-1116.

19. Kozicky, O.J., Brandt, L.J., Ledermann, M. \& Milku, M. Splenic amyloidosis: a case report of spontaneous splenic rupture and review of pertinent literature. Am J Gastroenterol 1987, 82: 582-587.

20. Pringle, S.D., McCartney, A.C. \& Cobbe, S.M. Spontaneous splenic rupture as complication of infective endocarditis. Int J Cardiol 1988, 19: 384-386.

21. Ronchi, L., de-Broucher, V., Pavlovitch, J.M., Poirier, T., Ronchi, C. \& Vilain, G. Spontaneous rupture of the spleen during the development of chronic pancreatitis. One case. [Engl abstract] Ann Gastroenterol Hepatol (Paris) 1985, 21: 137-139.

22. Houry, S., Sellem, G. \& Huguier, M. Spontaneous rupture of the spleen in chronic panceatitis. [Engl abstract] Gastroenterol Clin Biol 1985, 9: 918-921.

23. Van Landingham, S.B., Rawls, D.E. \& Roberts, J.W. Pathological rupture of the spleen associated with hepatitis A. Arch Surg 1984, 119: 224-225. 
24. Thijs, J.C., Schneider, A.J. \& van-Kordelaar, J.M. Spontaneous rupture of the spleen complicating portal hypertension. Intensive Care Med 1983, 9: 299-300.

25. Auerbach, R.D., Kohorn, E.I., Cornelius, E.A. \& Chambers, J.T. Splenosis: a complicating factor in total abdominal hysterectomy. Obstet Gynecol 1985, 65 (Suppl 3): 65s-68s.

26. Belhassen, A., Aubineau, J.M., Bouverne, B. \& Gautier, P. Splenosis: an unrecognised cause of pelvic pain. [Engl abstract] J Gynecol Obstet Biol Reprod (Paris) 1987, 16: 335-338.
27. Watson, W.J., Sundwall, D.A. \& Benson, W.L. Splenosis mimicking endometriosis. Obstet Gynecol 1982, 59 (suppl 6): $51 s-53 \mathrm{~s}$. 